\title{
Identification of somatic $A P C$ mutations in recurrent desmoid tumors in a patient with familial adenomatous polyposis to determine actual recurrence of the original tumor or de novo occurrence
}

\author{
Takeo Iwama $\cdot$ Kouki Kuwabara $\cdot$ \\ Mineko Ushiama · Teruhiko Yoshida • \\ Kokichi Sugano $\cdot$ Hideyuki Ishida \\ Published online: 15 August 2008 \\ (c) The Author(s) 2008. This article is published with open access at Springerlink.com
}

\begin{abstract}
A 25-year-old female with familial adenomatous polyposis (FAP) presented with an abdominal tumor just below the scar due to a colectomy performed 15 months previously. This tumor (tumor A) measured $7 \mathrm{~cm}$ in diameter, was diagnosed as a desmoid tumor of the abdominal wall, and was excised. Despite the subsequent administration of sulindac ( $300 \mathrm{mg}$ daily for 1 year), a desmoid tumor recurred at the same site. Excision was performed again when the tumor was $8 \mathrm{~cm}$ in diameter, and examination revealed it to consist of a large tumor (B) and a small tumor $(\mathrm{C})$ that bulged out from tumor B. Germ-line $A P C$ analysis showed a $\mathrm{C}$ deletion at codon 1460 resulting in a stop codon. Two somatic mutations were observed in tumor A: a TCAA deletion at codon 1068 and a deletion of a codon at bp 1192-2097. In tumor B, a somatic mutation was found at codon 1041 changing CAA to TAA. We could not detect any somatic mutations in tumor $\mathrm{C}$. We conclude that somatic mutation analysis of the $A P C$ gene
\end{abstract}

T. Iwama $(\bowtie)$

Department of Surgery, Kyoundo Hospital, Kanda Surugadai

1-8, Chiyoda-Ku, Tokyo 101-0062, Japan

e-mail: Iwama@po.kyouno.jp

K. Kuwabara $\cdot$ H. Ishida

Department of Digestive Tract and General Surgery,

Saitama Medical Center, Saitama Medical University,

1981 Tsujido-machi, Kamoda, Kawagoe-shi,

Saitama 350-8550, Japan

M. Ushiama $\cdot$ T. Yoshida

Genetics Division, National Cancer Center Research Institute,

Tsukiji 5-1-1, Chuo-Ku, Tokyo 104-0045, Japan

\section{K. Sugano}

Oncogene Research Unit/Cancer Prevention Unit, Tochigi

Cancer Center Research Institute, Yonan 4-9-13, Utsunomiya,

Tochigi 320-0834, Japan can be used to identify whether a recurrent desmoid tumor in a patient with FAP is a new primary tumor or a recurrence from microscopic remnants of the original tumor.

Keywords $\quad A P C$ gene - Desmoid tumor - Familial adenomatous polyposis - Origin of a recurrent desmoid tumor $\cdot$ Recurrence $\cdot$ Somatic mutation

\section{Introduction}

Desmoid tumors occur at a frequency of about 7\% (3.5$17.5 \%)$ in patients with familial adenomatous polyposis (FAP) who have had abdominal surgery [1, 2]. Surgical resection may be the chosen approach for treating a symptomatic desmoid tumor if it does not regress spontaneously and repeated pharmacological treatments fail to control the tumor. Surgical treatment is associated with the considerable recurrence rate of $20-80 \%$ [3]. When a desmoid tumor appears near the excised tumor, it is usually difficult to conclusively determine whether the recurrent tumor is a new occurrence or an actual recurrence from the microscopic remnants of the original tumor. However, the identification of the origin of recurrent tumors is useful in determining the treatment of the tumors. Several studies have reported that desmoid tumors frequently show somatic mutations coexistent with germ-line mutations of the $A P C$ gene [4-6]. Consequently, an analysis of somatic mutations in these tumors may elucidate the origin of the recurred tumors.

\section{Case report}

A 25-year-old female with FAP presented with an abdominal tumor at the scar due to a total colectomy performed 12 months previously by a laparoscopic procedure. 


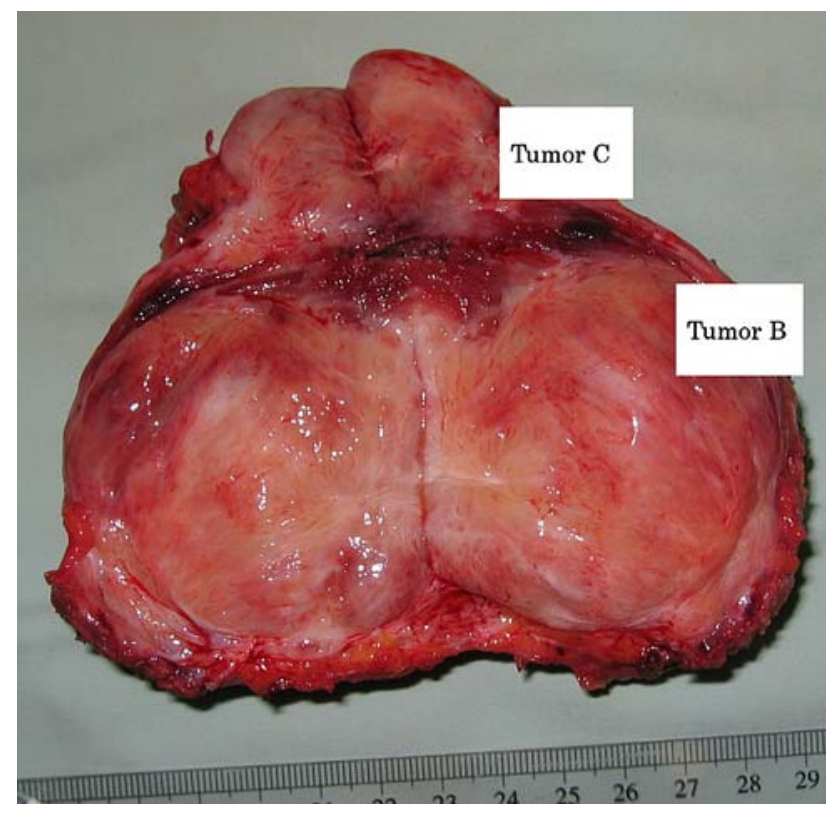

Fig. 1 Monoclonal phase of the recurred abdominal desmoid tumor composed of a large tumor $(B)$ and a small tumor $(C)$

Her father and grandmother died of colon cancer associated with FAP at 43 and 50 years of age, respectively. Her younger sister died at the age of 21 due to a desmoid tumor in the mesentery that caused intestinal obstruction following gynecological surgery performed at another hospital; she had also been diagnosed with FAP.

The patient had gastric polyposis, dental abnormality, and osteomas in the jaw. The abdominal tumor measured $3 \mathrm{~cm}$ in maximal diameter and grew to $7 \mathrm{~cm}$ during the following 3 months. At this stage the tumor was excised and diagnosed as a desmoid tumor infiltrating the rectus muscle (tumor A). Although the patients was subsequently treated with sulindac ( $300 \mathrm{mg} /$ day), a tumor recurred in the following 12 months at a site adjacent to tumor A. The recurrent tumor measured $8 \mathrm{~cm}$ in maximal diameter and was excised. It was found to consist of a large tumor $(7 \mathrm{~cm}$; tumor B) and a small tumor $(3 \mathrm{~cm}$; $)$ that bulged out from the large one (Fig. 1).
After providing genetic counseling specific to her condition and receiving her written consent, we examined the tumors for $A P C$ mutations. DNA and RNA were extracted from peripheral blood leukocytes by a standard procedure, and DNA was extracted from the frozen tissue samples of the desmoid tumors. A germ-line mutation was identified from the peripheral blood samples by the protein truncation test (PTT) on reverse-transcription (RT)-PCR products corresponding to exons 1-14 and on genomic fragments of exon 15 (PT4-PT7); this was followed by direct DNA sequencing of the PCR-amplified segments using standard methods with minor modifications [7-9]. For the tumor tissue samples, the PTT was applied to exon 15 only because high-quality RNA samples covering exons 1-14 were not available by RT-PCR. However, direct sequencing of PCR-amplified genomic fragments of exons 1-14 was carried out on all tissue samples.

Three APC mutations were detected in tumor $\mathrm{A}$ (Table 1): a germ-line mutation detected in a blood sample in which $\mathrm{C}$ was deleted at codon 1460 , producing the stop signal ATT at codon 1472 in the mutated $A P C$, and two somatic mutations. The same germ-line mutation was confirmed in tumors B and C. In tumor B, we also found a somatic mutation distinct from those of tumor A (Table 1). No somatic mutations were detected in tumor C. A mesenteric desmoid tumor was diagnosed 28 months after the last surgery. The patient was treated with doxorubicin at $24 \mathrm{mg}$ /day per body weight (days 1-4) and dacarbazine at $300 \mathrm{mg} /$ day per body weight (days $1-4$ ), every 4 weeks for five cycles. This therapy resulted in a $30 \%$ decrease in the diameter of the tumor [10]. Follow-up has been uneventful, and the tumor has been stable for 3 years from the last operation until the time of this report.

\section{Discussion}

Postoperative desmoid tumors are a nuisance to patients with FAP [11]. To date, only a small quantity of epidemiological data is available on desmoid tumors in large

Table 1 Tumor-specific $A P C$ mutations

\begin{tabular}{llr}
\hline Tumor & Detected $A P C$ mutations $^{\mathrm{a}}$ & \\
\hline Tumor A & Codon 1460: GCT to GT (C) deletion) ${ }^{\mathrm{b}}$ & $\begin{array}{c}\text { Deletion of TCAA at codon 1066 producing TAA } \\
\text { at codon 1124 in the mutated gene } \\
\text { Deletion of codon at bp 1192-2097 producing TAA } \\
\text { at codon 1194 in the mutated gene }\end{array}$ \\
Tumor B & Codon 1460: GCT to GT (C) deletion) ${ }^{\mathrm{b}}$ Codon 1041: CAA to TAA & - \\
\hline
\end{tabular}

a Sequencing of exons 1-14 revealed no mutations in these tumors

b Detected germ-line $A P C$ mutation producing the stop signal TAA at codon 1472 in the mutated $A P C$ 
populations of patients with FAP. The reasons for this lack of information are: (1) desmoid tumors may occur spontaneously and/or following surgical intervention; (2) they frequently exist at a subclinical level; (3) they may disappear or shrink without specific treatment. Although desmoid tumors have no propensity to metastasize, the mortality rate among patients varies. Iwama et al. [1] reported 71 cases (45 women, 26 men) of desmoid tumor among 1050 FAP cases in their registry; eight of the 71 patients $(11 \%)$ had died of desmoid tumor. Church et al. [12] applied a staging system to 101 patients with intraabdominal desmoid tumors associated with FAP. Their mortality rate was $0 \%$ in Stage I, $0 \%$ in Stage II, $15 \%$ in Stage III, 44\% in Stage IV, and 12\% (12/101) overall. The polyposis registry of St. Mark's Hospital identified 32 desmoid tumors that had been removed from 20 patients with FAP during the preceding 10 years [13]; there was no mortality among these patients resulting from desmoid disease. According to a Danish national registry compiled by Bülow [14], desmoid tumor was the fifth (3\%) most common cause of death among 175 deceased FAP patients. In contrast, Arvanitis [15] reported that, among his FAP patients, desmoid disease was the second most common (10.9\%) cause of death following colorectal cancer $(58.2 \%)$.

Surgical treatment of a desmoid tumor in patients with FAP is associated with a high recurrence rate of up to $45 \%$ (20-80\%) following excision of a tumor [3, 16]. Recurrence near the site of the original tumor has been ascribed to the presence of microscopic remnants of the excised tumor, although to date there has been no conclusive evidence for this. Because desmoid tumors are monoclonal fibroblastic proliferations arising from fibrotic or aponeurotic structures [17, 18], we may be able to distinguish actual recurrence of the original tumor from de novo occurrence due to surgical stimulation based on the detection of somatic APC mutation in the recurrent tumors. In this study, the sample from tumor A may have been a mixture of at least two different tumors, although there is also the possibility that tumor A carried a double somatic mutation in a single clone. The recurrent tumors B and $\mathrm{C}$, which developed following the excision of tumor A, could be diagnosed as multiple primary tumors by their mutation signatures, which were distinct from those of tumor A. Tumor $\mathrm{C}$ probably carries a different somatic mutation from tumor $\mathrm{A}$ and $\mathrm{B}$; if this were not the case, the same somatic mutation in A or B would have been detected from the high-quality DNA.

During their treatment of fibromatosis in patients without FAP, Gronchi et al. [19] observed that the chance that a recurred tumor would occur again was higher than that of the original tumor recurring when they are surgically treated. Sturt et al. [20] observed that there was a genetic or familial predisposition to desmoid tumors in patients with FAP despite the fact that no specific hot spots have been found in the $A P C$ gene. These observations are compatible with our results if recurrence of a desmoid tumor at the wound site is more dependent on the genetic traits of the patients than on surgical quality. Desmoid tumors tend to occur at a younger age than does colorectal cancer, and the former are more frequent in females than males [1,21]. Given these findings and the fact that the sister of our patient died of a desmoid tumor, we should have refrained from performing a colectomy and have followed the patient with close endoscopic surveillance and polypectomy for as long as possible.

Open Access This article is distributed under the terms of the Creative Commons Attribution Noncommercial License which permits any noncommercial use, distribution, and reproduction in any medium, provided the original author(s) and source are credited.

\section{References}

1. Iwama T, Mishima Y, Utsunomiya J (1993) The impact of familial adenomatous polyposis on the tumorigenesis and mortality at the several organs; its rational treatment. Ann Surg 217(2):101-108. doi:10.1097/00000658-199302000-00002

2. Itoh H, Ikeda S, Oohata Y et al (1988) Treatment of desmoid tumors in Gardner's syndrome. Dis Colon Rectum 31(6):459461. doi:10.1007/BF02552617

3. Clark SK, Phillips RK (1996) Desmoids in familial adenomatous polyposis. Br J Surg 838(11):1494-1504. doi:10.1002/bjs.1800 831105

4. Yoshida MA, Ikeuchi T, Iwama T et al (1991) Chromosome changes in desmoid tumors developed in patients with familial adenomatous polyposis. Jpn J Cancer Res 82(8):916-921

5. Okamoto M, Sato C, Kohno Y et al (1990) Molecular nature of chromosome $5 \mathrm{q}$ loss in colorectal tumors and desmoids from patients with familial adenomatous polyposis. Hum Genet 85(6): 595-599. doi:10.1007/BF00193581

6. Miyaki M, Konishi M, Iwama T et al (1993) Coexistence of somatic and germ-line mutation of $A P C$ gene in desmoid tumors from patients with familial adenomatous polyposis. Cancer Res 53(21):5079-5082

7. Van der Luijit RB, Kahn MP, Vasen HFA et al (1997) Molecular analysis of the APC gene in 105 Dutch kindreds with familial adenomatous polyposis: 67 germline mutations identified by DGGE, PTT, and southern analysis. Hum Mutat 9(1):7-16. doi:10.1002/ (SICI)1098-1004(1997)9:1<7::AID-HUMU2>3.0.CO;2-8

8. Heinimann K, Thompson A, Locher A et al (2001) Nontruncating APC germ-line mutations and mismatch repair deficiency play a minor role in APC mutation-negative polyposis. Cancer Res 61(20):7616-7622

9. Orita M, Suzuki Y, Sekiya T et al (1989) Rapid and sensitive detection of point mutations and DNA polymorphisms using the polymerase chain reaction. Genomics 5(4):874-879. doi:10.1016/ 0888-7543(89)90129-8

10. Lynch HT, Fitzgibbons R Jr, Chong S et al (1994) Use of doxorubicin and dacarbazine for the management of unrespectable intra-abdominal desmoid tumors in Gardner's syndrome. Dis Colon Rectum 37(3):260-267. doi:10.1007/BF02048164

11. Whiting J, Portnoy M, Litchman C (2005) Desmoid Tumor Research Foundation. Available at: http://www.dtrf.org/dtrf index.html. Accessed 15 June 2008 
12. Church J, Lynch C, Neary P et al (2008) A desmoid tumorstaging system separates patients with intra-abdominal, familial adenomatous polyposis-associated desmoid disease by behavior and prognosis. Dis Colon Rectum 51:897-901. doi:10.1007/ s10350-008-9232-5

13. Latchford AR, Sturt NJ, Neale K et al (2006) A 10-year review of surgery for desmoid disease associated with familial adenomatous polyposis. Br J Surg 93(10):1258-1264. doi:10.1002/bjs. 5425

14. Bülow S (2003) Results of national registration of familial adenomatous polyposis. Gut 52(3):742-746. doi:10.1136/gut.52.5.742

15. Arvanitis ML, Jagelman DG, Fazio V et al (1990) Mortality in patients with familial adenomatous polyposis. Cis Colon Rectum 33(8):639-642. doi:10.1007/BF02150736

16. Heiskanen I, Järvinen HJ (1996) Occurrence of desmoid tumours in familial adenomatous polyposis and results of treatment. Int $\mathbf{J}$ Colorectal Dis 11(14):157-162. doi:10.1007/s003840050034

17. De Wever I, Dal Cin P, Fletcher CD et al (2000) Cytogenetic, clinical, and morphologic correlations in 78 cases of fibromatosis: a report from the CHAMP Study Group. Chromosomes and morphology. Mod Pathol 13(10):1080-1085. doi:10.1038/modpathol. 3880200

18. Li M, Cordon-Cardo C, Gerald WL et al (1996) Desmoid fibromatosis is a clonal process. Hum Pathol 27(9):939-943. doi: 10.1016/S0046-8177(96)90221-X

19. Gronchi A, Casali PG, Mariani L et al (2003) Quality of surgery and outcome in extra-abdominal aggressive fibromatosis: a series of patients surgically treated at a single institution. J Clin Oncol 21(7):1390-1397. doi:10.1200/JCO.2003.05.150

20. Sturt NJH, Gallagher MC, Bassett P et al (2004) Evidence for genetic predisposition to desmoid tumours in familial adenomatous polyposis independent of the germline APC mutation. Gut 53(12):1832-1836. doi:10.1136/gut.2004.042705

21. Gurbuz AK, Giardiello FM, Petersen GM et al (1994) Desmoid tumours in familial adenomatous polyposis. Gut 35(3):377-381. doi:10.1136/gut.35.3.377 